\title{
Editorial \\ Secondary Metabolites and Their Applications
}

\author{
Eugenia Gallardo ${ }^{1,2, *(1)}$ and Ana M. L. Seca ${ }^{3,4, *(D)}$
}

1 Centro de Investigação em Ciências da Saúde (CICS-UBI), Universidade da Beira Interior, Av. Infante D. Henrique, 6200-506 Covilhã, Portugal

2 Laboratório de Fármaco-Toxicologia, UBIMedical, Universidade da Beira Interior, Estrada Municipal 506, 6200-284 Covilhã, Portugal

3 cE3c-Centre for Ecology, Evolution and Environmental Changes / Azorean Biodiversity Group \& Faculty of Sciences and Technology, University of Azores, Rua Mãe de Deus, 9500-321 Ponta Delgada, Portugal

4 LAQV-REQUIMTE, Department of Chemistry, Campus de Santiago, University of Aveiro, 3810-193 Aveiro, Portugal

* Correspondence: egallardo@fcsaude.ubi.pt (E.G.); ana.ml.seca@uac.pt (A.M.L.S.); Tel.: +351-275-329-002 (E.G.); +351-296-650-174 (A.M.L.S.)

check for updates

Citation: Gallardo, E.; Seca, A.M.L. Secondary Metabolites and Their Applications. Appl. Sci. 2022, 12, 2317. https://doi.org/10.3390/ app12052317

Received: 15 February 2022 Accepted: 17 February 2022 Published: 23 February 2022

Publisher's Note: MDPI stays neutral with regard to jurisdictional claims in published maps and institutional affiliations.

Copyright: () 2022 by the authors. Licensee MDPI, Basel, Switzerland. This article is an open access article distributed under the terms and conditions of the Creative Commons Attribution (CC BY) license (https:/ / creativecommons.org/licenses/by/ $4.0 /)$.

\section{Introduction}

The identification of secondary metabolites present in both terrestrial and marine species continues to be a fundamental and privileged path for the emergence of new and fundamental natural products available on the market with very different applications. For example, aplidine is a new natural anticancer agent, and it was approved in Australia in 2018 to treat multiple myeloma [1] and was isolated from the first time from tunicate Aplidium albicans Milne Edwards. (+)-Nootkatone is a natural sesquiterpene compound, found in very small amounts in several species such as Chamaecyparis nootkatensis (D. Don) Sudworth, Chrysopogon zizanioides (L.) Roberty and Citrus paradisi Macfad., which exhibits highly appreciated organoleptic properties and is, therefore, highly demanded as a flavoring agent or adjuvant in the food, pharmaceutical and perfumery industries [2,3]. This same natural secondary metabolite is applied as insecticide and acaricide, and it was very recently authorized by United Sates Environmental Protection Agency to be include on formulations to control the spread of mosquitoes that transmit infectious diseases as dengue and zika [4]. And who does not know the application of ascorbic acid, found for example in acerola and lemon fruits, as an antioxidant agent [5], widely used by the food industry?

The successful application of secondary metabolites in diverse requests often involves the use of, more or less, complex mixtures of metabolites, extracted by different methods and from different natural sources, but whose chemical composition and active principles are perfectly established. For example, there are the defined botanical mixtures, called natural product botanicals, which are recognized by the FDA as medicinal entities, successfully used in clinical therapy for the treatment of various diseases. This is the case of the mixture of the secondary metabolites of Solanum sodomaeum L., solamargine, solasonine, and monoand di-glycosides derivatives of solasodine, approved by the European Medicine Agency (trade name Curaderm) for the treatment of basal cell carcinoma of the skin [6].

One area in which the application of secondary metabolites mixtures rather than of pure compounds is common is in the formulation of biopesticides. For example, the insecticide Grandevo ${ }^{\circledR}$ is a mixture of metabolites produced in the fermentation of Chromobacterium subtsugae, which includes pigments from the violacein family and proteins that are repellent and antifeeding [7].

Despite the great successes already achieved regarding the secondary metabolites' identification and the development of new applications for these metabolites, this is an area of research that should not slow down. Research must continue identifying and isolating secondary metabolites in unexplored natural sources; new methodologies for extracting secondary metabolites should be tested and optimized to develop greener and more 
efficient processes; pure secondary metabolites and chemically characterized mixtures must be tested in different biological activities in order to enhance new applications responding to the growing needs of humanity.

The Special Issue of Applied Sciences, "Advances in Applications of Natural Bioactive Compounds", aims to contribute to the desired continuous advance in this scientific field, bringing together publications focused on the most recent advances in the identification of secondary metabolites from terrestrial and marine sources, in new extractive methodologies, and in proposals for applications that add value to natural resources and contributes to a more sustainable development.

\section{Contributions}

This Special Issue brings together seven research articles and four review articles presenting the latest advances in the study of secondary metabolites from different natural sources and their potential applications. The scientific results are presented that led to the identification of secondary metabolites in samples of terrestrial and marine origin, obtained by classic and innovative extractive methodologies, as well as studies to evaluate their effect in different areas such as health, biopesticides, etc.

Invasive alien species are recognized for triggering various impacts, such as habitat modification, alteration of community structure, and affecting ecosystem processes. The characterization of secondary metabolites in invasive species could be a way of valuing and increasing the search for available biomass promoting its harvest and contribute to the conservation of biodiversity and sustainability of the ecosystem. This is one of the objectives of the studies carried out by Paula et al. [8] and Pinto et al. [9], in which the secondary metabolite composition of two invasive species, one terrestrial (Acacia dealbata L.) and one marine (seaweed Asparagopsis armata Harvey), respectively, are presented. The results show that the hydroethanolic extract of non-mature flowers of Acacia dealbata exhibits the greatest potential as an antioxidant and acetylcholinesterase inhibitor, these activities being correlated with the higher content of chalcones present [8]. These authors suggest the extract as a source of compounds capable of improving brain functions, while collecting the flower at an early stage of flowering contributes to interrupting the plant's reproduction, which will help to control its invasive potential. Pinto et al. [9] address new perspectives for the valuation of Asparagopsis armata, an invasive alga in Europe, and have determined the profile of the secondary metabolites of this species using GC-MS and UHPLC-MS techniques. The authors established the species as a source of halogenated compounds and fatty acids, with 1,4-dibromobuten-1-ol and palmitic acid being the two most abundant compounds identified in the lipophilic fraction, while in the polar fraction, brominated phenolic compounds derived from cinnamic acid are predominant. This work also shows that changing the extraction method modifies the metabolomic profile of the obtained extract. The use of ethanol under microwave energy extracted almost exclusively one compound, the 2,3-diphenylpropanoic acid derivative with one hydroxyl group and two bromine atoms in each aromatic ring [9].

The Martí-Quijal group [10] also uses samples of marine origin, in this case the cyanobacterium Arthrospira platensis Gomont, and optimizes the extraction with pulsed electric fields to propose a more selective, sustainable, and efficient methodology to extract chlorophylls, carotenoids, and phenolic compounds, which have applications as nutritional and antioxidants agents.

In recent years, natural phytotoxic compounds derived from plants have been extensively investigated for herbicidal properties and have been shown to suppress weeds. These compounds can then be used as promising models for standard bioherbicides. In this sense, Rob et al. [11] have demonstrated in their manuscript for the first time the presence of methyl phloretate in Garcinia xanthochymus Hook.f. ex T.Anderson, as well as its phytotoxic properties. Vanillic acid was also identified. Both compounds have significant growth inhibitory activities in watercress and timothy, demonstrating as such the potential of the leaves of Garcinia xanthochymus in weed management. 
The leaves of Afzelia xylocarpa (Kurz) Craib. were investigated as a natural source of herbicides. Krumsri et al. [12] have identified vanillic acid and trans ferulic acid as the major bioactive compounds, both being responsible for the phytotoxic activity of Afzelia xylocarpa. The concentration of those compounds and differences in the sensitivity of the plant models are key to their phytotoxic action. Additionally, a mixture of both compounds at low concentrations had synergistic effects concerning phytotoxic activity.

Shedding light on the mechanisms of action that justify the observed secondary metabolite bioeffects is an essential point where more research is needed before it can advance towards clinical therapy. The secondary metabolite thymoquinone can be extracted from the seed oil of Nigella sativa L. (black seed oil) and exhibits several biological activities [13], among which are relevant antitumor properties, and has already been the subject of clinical studies (ClinicalTrials.gov Identifier: NCT03208790). However, its mechanism of action is not yet fully understood. Alhosin et al. [14] make a very significant contribution to clarifying this point. They show that thymoquinone, unlike doxorubicin, specifically targets the oncogene UHRF1. Probably through the downregulation of HAUSP, thymoquinone induces the rapid ubiquitination of UHRF1, an essential event for the induction of cancer cell apoptosis without, however, affecting the Bcl-2 oncogene [14].

The total synthesis of natural secondary metabolites contributes not only to confirm the proposed chemical structure of the natural compound but also to satisfy the demand for more compounds for different applications without degrading the environment. Thus, the work by Kim et al. [15] is a great contribution to the development of new applications for the secondary metabolite Aaptoline B, a pyrroloquinoline alkaloid extracted from the marine sponge Aaptos aaptos Schmidt and considered a privileged scaffold in drug discovery. The authors suggest a short but comprehensive and efficient synthetic process for Aaptolin B and demonstrate, using Caenorhabditis elegans as a model of the Parkinson's disease-like neuronal environment, that this compound exhibits a neuroprotective effect [15]. Thus, the door is open for investigation into a new application for this secondary metabolite.

Laboratory synthesis is not the only strategy applied to obtain new and greater amounts of bioactive secondary metabolites. Streptomyces is a group of Gram-positive bacteria capable of biosynthesizing a wide range of natural compounds from different families, with different commercial applications and high economic value [16]. Doxorubicin, an antitumor antibiotic, and avermectin, used to treat parasitic worms and insect pests, are just two well-known examples. However, the potential of these microorganisms to produce secondary metabolites is much greater than achieved so far. The problem is, under laboratory conditions, many of the genes responsible for this biosynthesis remain silent. Heterologous biosynthesis has been an applied approach to overcome this limitation. Pham et al. [17] publish in this Special Issue a review of the literature on the latest advances in heterologous biosynthesis to produce natural compounds from Streptomyces, which include the overexpression/deletion of regulatory genes, promoter replacement strategies, and engineering of ribosomes.

On the other hand, many natural secondary metabolites, semi-synthesized or synthesized in the laboratory or by a biotechnological approach, exhibit excellent pharmacodynamics but very poor pharmacokinetic properties. The development of nano delivery systems has been a successful way to overcome the pharmacokinetic limitations of many natural compounds, allowing them to broaden their medicinal application [18]. Sindhu et al. [19] present in this Special Issue a review of the literature on the development of nano formulations involving natural compounds with application in the treatment of cardiovascular diseases, highlighting those with the most significant results for the prevention and treatment of this type of disease, that is, cases involved in clinical studies.

As referred to before, invasive species are considered one of the most significant global threats to biodiversity. However, these species can also be quite helpful to humans, providing a complex number of services, which makes it difficult to assess their positive and negative effects. Caramelo et al. [20] review the knowledge of the chemical composition and the discovery of the biological properties of one such invasive alien species-Ailanthus 
altissima (Mill.) Swingle - and its potential use as medicine and additive by the pharmacy and food industries. Methods for the extraction and detection to know the chemical composition of extracts have been discussed in detail by the authors.

Finally, Silva-Beltrán et al. [21] evaluate the chemical profiles of propolis produced in Brazil and Mexico. Both countries' geographic and ecosystem differences provide propolis with different chemical profiles. However, data in both countries indicate that more research is still needed to determine the optimal characteristics of propolis and its components, such as period of intake or type of extract to use before it can be administered to humans as medicine The authors have also review the use of propolis as environmental bioindicator, concluding that more studies are necessary.

In the guest editors' opinion, this Special Issue of Applied Sciences brings together great contributes to the desired continuous advance in secondary metabolites and the development of new applications for these metabolites. In fact, the published papers are focused on the most recent advances in the identification of secondary metabolites from terrestrial and marine sources obtained by classical and greener extractive methodologies. They are also focused on proposals for new applications that enhance the natural resources and their secondary metabolites, contributing to more sustainable development.

Author Contributions: A.M.L.S. and E.G. conceived, designed, and wrote the editorial. All authors have read and agreed to the published version of the manuscript.

Funding: This study was financed by Portuguese National Funds, through FCT-Fundação para a Ciência e Tecnologia, the European Union, QREN, FEDER, and COMPETE, through funding the cE3c center (UIDB/00329/2020), the LAQV-REQUIMTE (UIDB/50006/2020) and the CICS-UBI (UIDB/00709/2020 and UIDP/00709/2020).

Institutional Review Board Statement: Not applicable.

Informed Consent Statement: Not applicable.

Data Availability Statement: Not applicable.

Acknowledgments: Thanks are due to all the authors and peer reviewers for their valuable contributions to this Special Issue.

Conflicts of Interest: The authors declare no conflict of interest.

\section{References}

1. Newman, D.J.; Cragg, G.M. Natural Products as Sources of New Drugs over the Nearly Four Decades from 01/1981 to 09/2019. J. Nat. Prod. 2020, 83, 770-803. [CrossRef] [PubMed]

2. Fraatz, M.A.; Berger, R.G.; Zorn, H. Nootkatone-A biotechnological challenge. Appl. Microbiol. Biotechnol. $2009,83,35-41$. [CrossRef] [PubMed]

3. Fan, J.; Liu, Z.; Xu, S.; Yan, X.; Cheng, W.; Yang, R.; Guo, Y. Non-food bioactive product (+)-nootkatone: Chemistry and biological activities. Ind. Crops Prod. 2022, 177, 114490. [CrossRef]

4. United States Environmental Protection Agency. Available online: https://www3.epa.gov/pesticides/chem_search/ppls/0918 73-00001-20200807.pdf (accessed on 8 February 2022).

5. $\quad$ Ribeiro, J.S.; Santos, M.J.M.C.; Silva, L.K.R.; Pereira, L.C.L.; Santos, I.A.; Lannes, S.C.S.; Silva, M.V. Natural antioxidants used in meat products: A brief review. Meat Sci. 2019, 148, 181-188. [CrossRef] [PubMed]

6. Chase, T.; Cham, K.E.; Cham, B.E. Curaderm, the Long-Awaited Breakthrough for Basal Cell Carcinoma. Int. J. Clin. Med. 2020, 11, 579-604. [CrossRef]

7. Marrone, P.G. Pesticidal natural products-status and future potential. Pest Manag. Sci. 2019, 75, 2325-2340. [CrossRef] [PubMed]

8. Paula, V.; Pedro, S.I.; Campos, M.G.; Delgado, T.; Estevinho, L.M.; Anjos, O. Special Bioactivities of Phenolics from Acacia dealbata L. with Potential for Dementia, Diabetes and Antimicrobial Treatments. Appl. Sci. 2022, 12, 1022. [CrossRef]

9. Pinto, D.C.G.A.; Lesenfants, M.L.; Rosa, G.P.; Barreto, M.C.; Silva, A.M.S.; Seca, A.M.L. GC- and UHPLC-MS Profiles as a Tool to Valorize the Red Alga Asparagopsis armata. Appl. Sci. 2022, 12, 892. [CrossRef]

10. Martí-Quijal, F.J.; Ramon-Mascarell, F.; Pallarés, N.; Ferrer, E.; Berrada, H.; Phimolsiripol, Y.; Barba, F.J. Extraction of Antioxidant Compounds and Pigments from Spirulina (Arthrospira platensis) Assisted by Pulsed Electric Fields and the Binary Mixture of Organic Solvents and Water. Appl. Sci. 2021, 11, 7629. [CrossRef]

11. Rob, M.M.; Hossen, K.; Khatun, M.R.; Iwasaki, K.; Iwasaki, A.; Suenaga, K.; Kato-Noguchi, H. Identification and Application of Bioactive Compounds from Garcinia xanthochymus Hook. for Weed Management. Appl. Sci. 2021, 11, 2264. [CrossRef] 
12. Krumsri, R.; Ozaki, K.; Teruya, T.; Kato-Noguchi, H. Isolation and Identification of Two Potent Phytotoxic Substances from Afzelia xylocarpa for Controlling Weeds. Appl. Sci. 2021, 11, 3542. [CrossRef]

13. Malik, S.; Singh, A.; Negi, P.; Kapoor, V.K. Thymoquinone: A small molecule from nature with high therapeutic potential. Drug Discov. Today 2021, 26, 2716-2725. [CrossRef]

14. Alhosin, M.; Abdullah, O.; Kayali, A.; Omran, Z. A Fast Ubiquitination of UHRF1 Oncogene Is a Unique Feature and a Common Mechanism of Thymoquinone in Cancer Cells. Appl. Sci. 2021, 11, 7633. [CrossRef]

15. Kim, S.; Yang, W.; Han, Y.-T.; Cha, D.-S. Synthesis of Proposed Structure of Aaptoline B via Transition Metal-Catalyzed Cycloisomerization and Evaluation of Its Neuroprotective Properties in C. elegans. Appl. Sci. 2021, 11, 9125. [CrossRef]

16. Khushboo, K.P.; Dubey, K.K.; Usmani, Z.; Sharma, M.; Gupta, V.K. Biotechnological and industrial applications of Streptomyces metabolites. Biofuels Bioprod. Bioref. 2022, 16, 244-264. [CrossRef]

17. Pham, V.T.T.; Nguyen, C.T.; Dhakal, D.; Nguyen, H.T.; Kim, T.-S.; Sohng, J.K. Recent Advances in the Heterologous Biosynthesis of Natural Products from Streptomyces. Appl. Sci. 2021, 11, 1851. [CrossRef]

18. Saw, P.E.; Lee, S.; Jon, S. Naturally Occurring Bioactive Compound-Derived Nanoparticles for Biomedical Applications. Adv. Ther. 2019, 2, 1800146. [CrossRef]

19. Sindhu, R.K.; Goyal, A.; Algın Yapar, E.; Cavalu, S. Bioactive Compounds and Nanodelivery Perspectives for Treatment of Cardiovascular Diseases. Appl. Sci. 2021, 11, 11031. [CrossRef]

20. Caramelo, D.; Pedro, S.I.; Marques, H.; Simão, A.Y.; Rosado, T.; Barroca, C.; Gominho, J.; Anjos, O.; Gallardo, E. Insights into the Bioactivities and Chemical Analysis of Ailanthus altissima (Mill.) Swingle. Appl. Sci. 2021, 11, 11331. [CrossRef]

21. Silva-Beltrán, N.P.; Umsza-Guez, M.A.; Ramos Rodrigues, D.M.; Gálvez-Ruiz, J.C.; de Paula Castro, T.L.; Balderrama-Carmona, A.P. Comparison of the Biological Potential and Chemical Composition of Brazilian and Mexican Propolis. Appl. Sci. 2021, 11, 11417. [CrossRef] 